\title{
Decay studies of the long-lived states in ${ }^{186} \mathrm{Tl}$
}

M. Stryjczyk $\odot,{ }^{1,{ }^{*}}$ B. Andel, ${ }^{1,2}$ A. N. Andreyev, ${ }^{3,4}$ J. Cubiss, ${ }^{5,3}$ J. Pakarinen, ${ }^{6,7}$ K. Rezynkina, ${ }^{1,8}$ P. Van Duppen, ${ }^{1}$ S. Antalic ${ }^{2}$ T. Berry, ${ }^{9}$ M. J. G. Borge,,${ }^{10,5}$ C. Clisu, ${ }^{11}$ D. M. Cox,${ }^{12}$ H. De Witte, ${ }^{1}$ L. M. Fraile, ${ }^{13}$ H. O. U. Fynbo, ${ }^{14}$ L. P. Gaffney, ${ }^{5}$ L. J. Harkness-Brennan, ${ }^{15}$ M. Huyse, ${ }^{1}$ A. Illana,,${ }^{16,6,7}$ D. S. Judson,,${ }^{15}$ J. Konki, ${ }^{5}$ J. Kurcewicz,,${ }^{5}$ I. Lazarus, ${ }^{17}$ R. Lica, ${ }^{11,5}$ M. Madurga ${ }^{5}$ N. Marginean, ${ }^{11}$ R. Marginean, ${ }^{11}$ C. Mihai,,${ }^{11}$ P. Mosat, ${ }^{2}$ E. Nacher ${ }^{18}$ A. Negret, ${ }^{11}$ J. Ojala,${ }^{6,7}$ J. D. Ovejas, ${ }^{10}$ R. D. Page,${ }^{15}$ P. Papadakis, ${ }^{15,17}$ S. Pascu,${ }^{11}$ A. Perea,${ }^{10}$ Zs. Podolyák,,${ }^{9}$ V. Pucknell,${ }^{17}$ E. Rapisarda,${ }^{5}$ F. Rotaru,,${ }^{11}$ C. Sotty,,${ }^{11}$ O. Tengblad, ${ }^{10}$ V. Vedia, ${ }^{13}$ S. Viñals, ${ }^{10}$ R. Wadsworth, ${ }^{3}$ N. Warr, ${ }^{19}$ and K. Wrzosek-Lipska ${ }^{20}$

(IDS Collaboration)

${ }^{1}$ KU Leuven, Instituut voor Kern- en Stralingsfysica, Celestijnenlaan 200D, 3001 Leuven, Belgium

${ }^{2}$ Department of Nuclear Physics and Biophysics, Comenius University in Bratislava, 84248 Bratislava, Slovakia

${ }^{3}$ Department of Physics, University of York, YO10 5DD, York, United Kingdom

${ }^{4}$ Advanced Science Research Center, Japan Atomic Energy Agency, Tokai-mura, Japan

${ }^{5}$ ISOLDE, CERN, CH-1211 Geneva 23, Switzerland

${ }^{6}$ University of Jyväskylä, Department of Physics, P.O. Box 35, FI-40014, Jyväskylä, Finland

${ }^{7}$ Helsinki Institute of Physics, University of Helsinki, P.O. Box 64, FIN-00014, Helsinki, Finland

${ }^{8}$ Université de Strasbourg, CNRS, IPHC UMR7178, F-67000, Strasbourg, France

${ }^{9}$ Department of Physics, University of Surrey, Guildford GU2 7XH, United Kingdom

${ }^{10}$ Instituto de Estructura de la Materia, CSIC, Serrano 113 bis, E-28006 Madrid, Spain

${ }^{11}$ Horia Hulubei National Institute for Physics and Nuclear Engineering, RO-077125 Bucharest, Romania

${ }^{12}$ Department of Physics, Lund University, Lund S-22100, Sweden

${ }^{13}$ Grupo de Fisica Nuclear, Universidad Complutense de Madrid, 28040, Madrid, Spain

${ }^{14}$ Department of Physics and Astronomy, Aarhus University, DK-8000 Aarhus C, Denmark

${ }^{15}$ Department of Physics, Oliver Lodge Laboratory, University of Liverpool, Liverpool L69 7ZE, United Kingdom

${ }^{16}$ Istituto Nazionale di Fisica Nucleare, Laboratori Nazionali di Legnaro, Legnaro 35020, Italy

${ }^{17}$ STFC Daresbury, Daresbury, Warrington WA4 4AD, United Kingdom

${ }^{18}$ Instituto de Física Corpuscular, CSIC-Universidad de Valencia, E-46980, Valencia, Spain

${ }^{19}$ Institut für Kernphysik, Universität zu Köln, 50937 Köln, Germany

${ }^{20}$ Heavy Ion Laboratory, University of Warsaw, PL-02-093, Warsaw, Poland

(Received 3 June 2020; accepted 24 July 2020; published 18 August 2020)

Decay spectroscopy of the long-lived states in ${ }^{186} \mathrm{Tl}$ has been performed at the ISOLDE Decay Station at ISOLDE, CERN. The $\alpha$ decay from the low-spin $\left(2^{-}\right)$state in ${ }^{186} \mathrm{Tl}$ was observed for the first time and a half-life of $3.4_{-0.4}^{+0.5} \mathrm{~s}$ was determined. Based on the $\alpha$-decay energy, the relative positions of the long-lived states were fixed, with the $\left(2^{-}\right)$state as the ground state, the $7^{(+)}$state at $77(56) \mathrm{keV}$, and the $10^{(-)}$state at $451(56) \mathrm{keV}$. The level scheme of the internal decay of the ${ }^{186} \mathrm{Tl}\left(10^{(-)}\right)$state $\left[T_{1 / 2}=3.40(9) \mathrm{s}\right]$, which was known to decay solely through emission of 374-keV $\gamma$-ray transition, was extended and a lower limit for the $\beta$-decay branching $b_{\beta}>5.9(3) \%$ was determined. The extracted retardation factors for the $\gamma$ decay of the $10^{(-)}$state were compared to the available data in neighboring odd-odd thallium isotopes indicating the importance of the $\pi d_{3 / 2}$ shell in the isomeric decay and significant structure differences between ${ }^{184} \mathrm{Tl}$ and ${ }^{186} \mathrm{Tl}$.

DOI: 10.1103/PhysRevC.102.024322

\section{INTRODUCTION}

Neutron-deficient nuclei around the neutron midshell $N=$ 104 are interesting study cases from the nuclear structure

\footnotetext{
*marek.stryjczyk@kuleuven.be
}

Published by the American Physical Society under the terms of the Creative Commons Attribution 4.0 International license. Further distribution of this work must maintain attribution to the author(s) and the published article's title, journal citation, and DOI. point of view. This region of the nuclear chart is characterized by the occurrence of shape coexistence in atomic nuclei [1], a phenomenon, whereby different shapes coexist within one nucleus at low energy and which is interpreted as arising from proton excitations across the $Z=82$ proton shell closure. These coexisting structures have been observed in laser spectroscopy [2-5], $\alpha$ and $\beta$ decay [6-10], and Coulomb excitation [11] studies.

In the case of odd-odd thallium isotopes in this region, proton excitations across $Z=82$ leads to the existence of three long-lived states $[9,12]$. Previous studies suggest that the main configurations of these states are $\left[\pi s_{1 / 2} \otimes v p_{3 / 2}\right]$ for the 
$2^{-}$states $[3,6,12]$, a mixture of $\left[\pi s_{1 / 2} \otimes \nu i_{13 / 2}\right]$ and $\left[\pi d_{3 / 2} \otimes\right.$ $\left.v i_{13 / 2}\right]$ for the $7^{+}$states $[3,6,12]$, and $\left[\pi h_{9 / 2} \otimes v i_{13 / 2}\right]$ for the $10^{-}$states $\left(9^{-}\right.$in case of $\left.{ }^{188} \mathrm{Tl}\right)[3,12]$. Unlike in the neighboring ${ }^{184} \mathrm{Tl}$ and ${ }^{188} \mathrm{Tl}$ isotopes, the half-life and the decay of the $\left(2^{-}\right)$state in ${ }^{186} \mathrm{Tl}$, whose existence has been suggested from the $\alpha$-decay study of the low-spin isomeric state in ${ }^{190} \mathrm{Bi}$ [12], have not been reported yet.

Studying the decay pattern of the $10^{-}$isomers in $\mathrm{Tl}$ isotopes can reveal information on the decay of the intruderbased states in this region of the nuclear chart [8]. However, in the case of ${ }^{186} \mathrm{Tl}$, the $10^{(-)}$state is known to decay only through emission of a 374-keV $\gamma$ ray [13], while, as observed in ${ }^{184} \mathrm{Tl}$, the decay pattern is expected to be more complex, including multiple paths of internal decay, as well as $\alpha$ decay $[8,9]$.

In this paper, we present an extension of the isomeric decay scheme of the ${ }^{186} \mathrm{Tl}\left(10^{(-)}\right)$state, the observation of the $\alpha$ decay of the ${ }^{186} \mathrm{Tl}\left(2^{-}\right)$state and the relative positions of the three long-lived states in ${ }^{186} \mathrm{Tl}$. The results of the $\beta$-decay study of all three long-lived states will be published elsewhere [14].

\section{EXPERIMENTAL SETUP}

The experiment was performed at ISOLDE, CERN as a part of a campaign dedicated to measure the decays of ${ }^{182,184,186} \mathrm{Tl}$. A pure beam of ${ }^{186} \mathrm{Tl}$ was produced through spallation of a thick $\mathrm{UC}_{x}$ target by $1.4-\mathrm{GeV}$ protons, provided by the Proton Synchrotron Booster. The proton pulses (PP) were delivered every $1.2 \mathrm{~s}$ (or a multiple of this value) and grouped into the CERN proton supercycle structure (SC), whose length varied during the experiment from 20 to $40 \mathrm{PP}$. The produced thallium atoms effused from the target to a hot cavity, where they were selectively ionized in a two-step ionization process by the Resonance Ionization Laser Ion Source system [15]. The first step excitation was performed through the $6 p^{2} P_{1 / 2} \rightarrow 6 d^{2} D_{3 / 2}$ transition at $276.83 \mathrm{~nm}$ using a dye laser system. For the second step, the output from a Nd:YAG laser at $532 \mathrm{~nm}$ was used (details of the laser schemes are given in Ref. [15]). After the ionization, the ions were extracted from the ion source at $30-\mathrm{keV}$ energy and separated with respect to their mass-to-charge ratio by the High Resolution Separator [16]. To allow for the implantation of the thallium isotopes, a beam gate was open for $90 \mathrm{~ms}$ after each PP. The purified beam was implanted onto an aluminized mylar tape at the center of the ISOLDE Decay Station (IDS) [17]. After every SC, the tape was moved in order to remove daughter activities.

The SPEDE spectrometer was installed in the IDS decay chamber for the detection of conversion electrons and $\alpha$ particles [18]. It consists of 24-fold-segmented, 1-mm-thick annular silicon detector, which was cooled by circulating ethanol at about $-20^{\circ} \mathrm{C}$. It was situated at $15 \mathrm{~mm}$ in the backward direction of the beam, in front of the tape (see Fig. 1), and it covered about $14 \%$ of the solid angle. Behind the tape, a 0.5 -mm-thick $900-\mathrm{mm}^{2}$ PIPS silicon detector for the detection of $\beta$ particles was placed. Outside the IDS chamber, there were five high-purity germanium clover detectors (HPGe) used to detect the $\gamma$ radiation. The $\gamma$ energy and

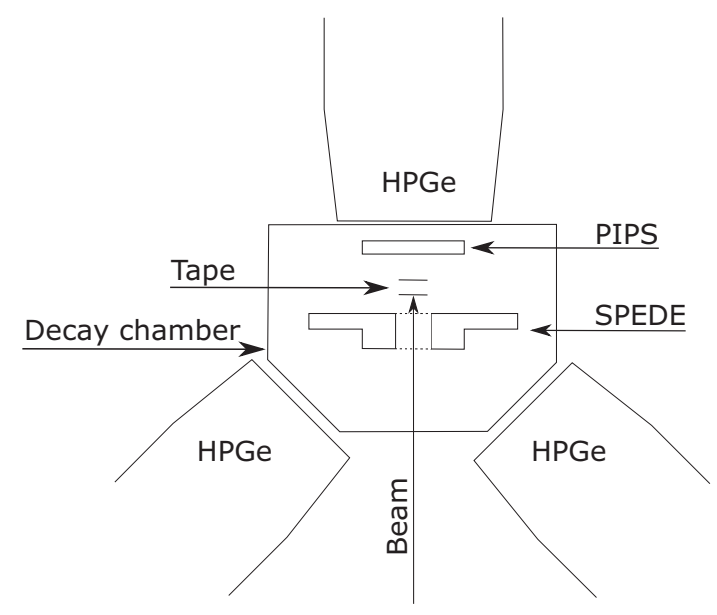

FIG. 1. A scheme of the detection system.

efficiency calibrations were performed by using an encapsulated ${ }^{152} \mathrm{Eu}$ source and a ${ }^{138} \mathrm{Cs}$ sample produced on-line and implanted onto the tape. At $1408 \mathrm{keV}$, the energy resolution was $2.7 \mathrm{keV}$ and the absolute $\gamma$ efficiency was $1.95(6) \%$. The SPEDE spectrometer energy calibration was performed using strong transitions with known energies from the decays of ${ }^{182,184,186} \mathrm{Tl}$ and ${ }^{138} \mathrm{Cs}$ for electrons and by using known $\alpha$ decays of ${ }^{184} \mathrm{Tl}$ and ${ }^{184} \mathrm{Hg}$ for $\alpha$ particles. The electron energy resolution was $6.3 \mathrm{keV}$ at $288 \mathrm{keV}$ and the $\alpha$ energy resolution was about $190 \mathrm{keV}$ at $6 \mathrm{MeV}$. All signals were collected in triggerless mode by using the Nutaq digital acquisition system [19] with 100-MHz sampling frequency.

\section{RESULTS}

\section{A. $\alpha$ decay of the $\left(2^{-}\right)$state}

Figure 2 shows the $\alpha$-decay energy spectrum registered by the SPEDE spectrometer during the experiment. Because of a limited energy resolution, it was not possible to resolve the fine structure $\alpha$ decays. Based on the (i) systematic trend of the $\alpha$-particle energies (see Figs. 1 and 9 in Ref. [9]), (ii) the previous experimental measurements of the $\alpha$ decay of ${ }^{186} \mathrm{Tl}$ and ${ }^{186} \mathrm{Hg}$ [20,21], and (iii) the behavior of the peak

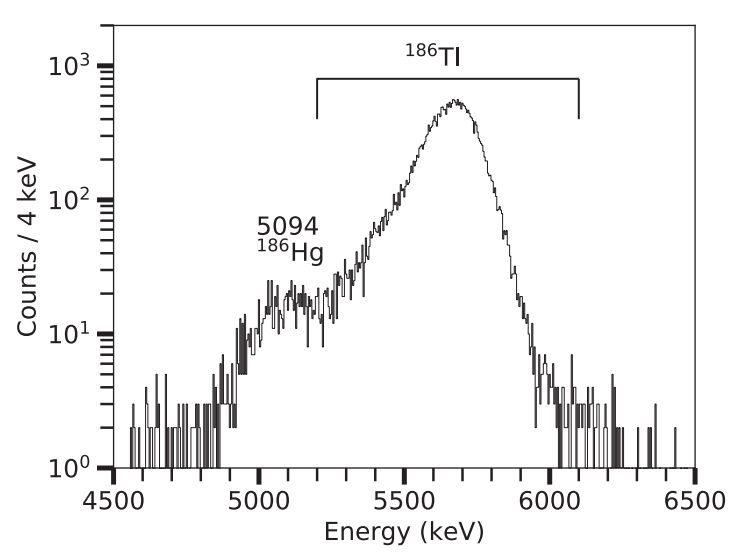

FIG. 2. The single- $\alpha$ energy spectrum registered with the SPEDE spectrometer. 
TABLE I. The relative intensities of the $\gamma$-ray transitions assigned to the decay of ${ }^{186} \mathrm{Tl}$ to ${ }^{182} \mathrm{Au}$, normalized to the intensity of the $129-\mathrm{keV}$ transition. The $202-\mathrm{keV}$ transition remains unplaced on the decay scheme.

\begin{tabular}{lccr}
\hline \hline $\begin{array}{l}E_{\gamma} \\
(\mathrm{keV})\end{array}$ & $I_{\gamma}^{\text {rel }}$ & $\begin{array}{l}E_{\text {livel }}^{\text {initial }} \\
(\mathrm{keV})\end{array}$ & $\begin{array}{r}E_{\text {level }}^{\text {final }} \\
(\mathrm{keV})\end{array}$ \\
\hline $104.1(2)$ & $24_{-4}^{+5}$ & 129.4 & 25.3 \\
$129.4(1)$ & 100 & 129.4 & 0.0 \\
$140.8(3)$ & $6.1_{-1.5}^{+1.7}$ & 270.2 & 129.4 \\
$143.7_{-0.8}^{+0.7}$ & $2.1_{-1.0}^{+1.2}$ & 273.1 & 129.4 \\
$201.5_{-0.5}^{+0.4}$ & $2.4_{-0.8}^{+1.0}$ & & \\
$273.1_{-0.7}^{+0.5}$ & $3.0_{-0.8}^{+1.0}$ & 273.1 & 0.0 \\
\hline \hline
\end{tabular}

intensity as a function of time, the peak around 5.7 MeV was associated with the $\alpha$ decay of ${ }^{186} \mathrm{Tl}$, while the peak at around $5.1 \mathrm{MeV}$ stems from a weak ground-state to ground-state $\alpha$ decay of ${ }^{186} \mathrm{Hg}$ to ${ }^{182} \mathrm{Pt}$ (branching ratio $b_{\alpha}=0.016(5) \%$, $E_{\alpha}=5094(15) \mathrm{keV}$ [21]).

In total, six $\gamma$-ray transitions have been observed in coincidence with the $\alpha$ particles associated with the decay of ${ }^{186} \mathrm{Tl}$ (see Table I and Fig. 3). Four of them, 104-, 129-, 144-, and 273-keV transitions, were previously observed and placed in the level scheme in the ${ }^{182} \mathrm{Hg}$ to ${ }^{182} \mathrm{Au} \beta$-decay study [22]. Based on the $\alpha-\gamma-\gamma$ coincidences (see Fig. 4), the newly identified $141-\mathrm{keV}$ transition was placed on top of the $129-\mathrm{keV}$ level, while the $202-\mathrm{keV}$ transition remains unplaced. The decay scheme is presented in Fig. 5.

Two levels at 129 and $273 \mathrm{keV}$ known from the $\beta$-decay study of ${ }^{182} \mathrm{Hg}\left(0^{+}\right)$are both suggested to have spin 1 or 2 and a negative parity [22]. The feeding of these low-spin levels in the $\alpha$ decay of ${ }^{186} \mathrm{Tl}$ suggests a low spin for the $\alpha$-decaying state, despite the fact that this state has a similar half-life to the $10^{(-)}$state (see Sec. III C). The existence of such level, with spin parity $\left(2^{-}\right)$, has been proposed from the $\alpha$-decay studies of ${ }^{190} \mathrm{Bi}$ [12]. Therefore, we suggest that the observed $\gamma$-ray

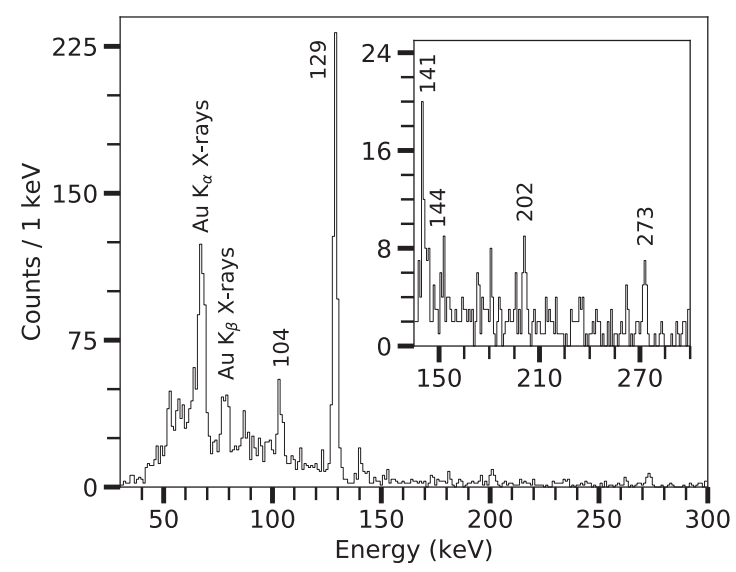

FIG. 3. The $\gamma$-ray energy spectrum with an energy gate on the 4550- to $6500-\mathrm{keV} \alpha$ particles and a coincidence time gate $70 \mathrm{~ns} \leqslant$ $\Delta T(\gamma-\alpha) \leqslant 300 \mathrm{~ns}$. An expanded view of the spectrum between 135 and $300 \mathrm{keV}$ is shown in the inset. Peaks are labeled according to corresponding transition energy in $\mathrm{keV}$.

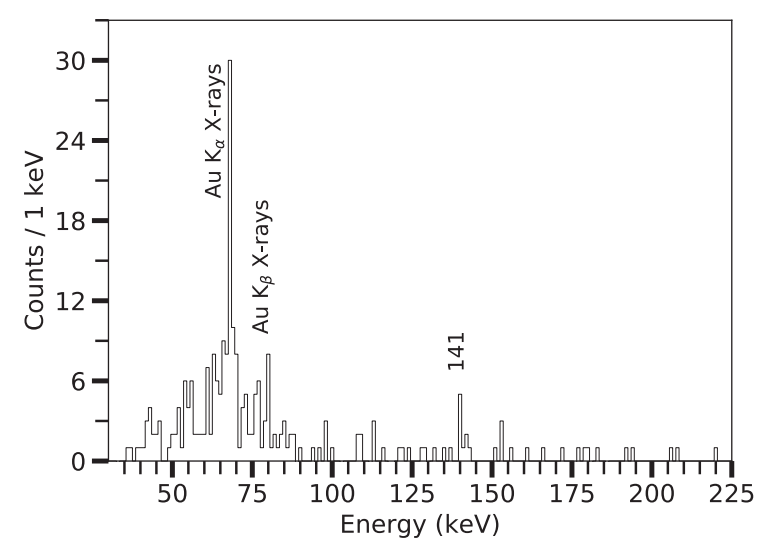

FIG. 4. The $\gamma$-ray energy spectrum with an energy gate on the 4550- to $6500-\mathrm{keV} \alpha$ particles and $129-\mathrm{keV} \gamma$ ray. Gold $\mathrm{K}_{\alpha}$ and $\mathrm{K}_{\beta}$ $\mathrm{x}$ rays as well as a peak at $141 \mathrm{keV}$ are present.

transitions placed in the decay scheme in Fig. 5 follow the $\alpha$ decay of the ${ }^{186} \mathrm{Tl}\left(2^{-}\right)$state.

To check the possible $\alpha$ decays of the other long-lived states in ${ }^{186} \mathrm{Tl}$, the number of counts in the $\alpha$-decay spectra gated on the 129- and 273-keV $\gamma$-ray transitions were compared to the number of counts in the single- $\alpha$ energy spectrum. To remove the influence of the 5094-keV $\alpha$ particles from the ${ }^{186} \mathrm{Hg}$ decay, the comparison range was set between 5.4
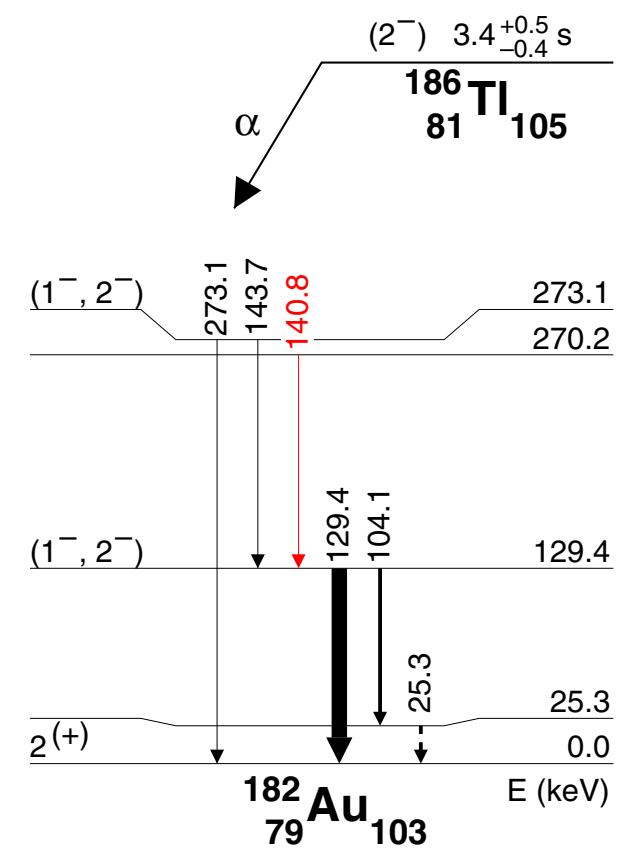

FIG. 5. The $\alpha$-decay scheme obtained in the present work. The $25-\mathrm{keV}$ transition has not been observed; however, it is known from the $\beta$-decay studies [22]. The spin parity of the ${ }^{182} \mathrm{Au}$ ground state is taken from Ref. [23] while the spin assignments of the excited states and the placement of the $\gamma$-ray transitions are taken from Ref. [22], with an exception of the newly observed 141-keV transition (plotted in red). The spin parity of ${ }^{186} \mathrm{Tl}$ is taken from Ref. [12] and the halflife comes from our analysis. 


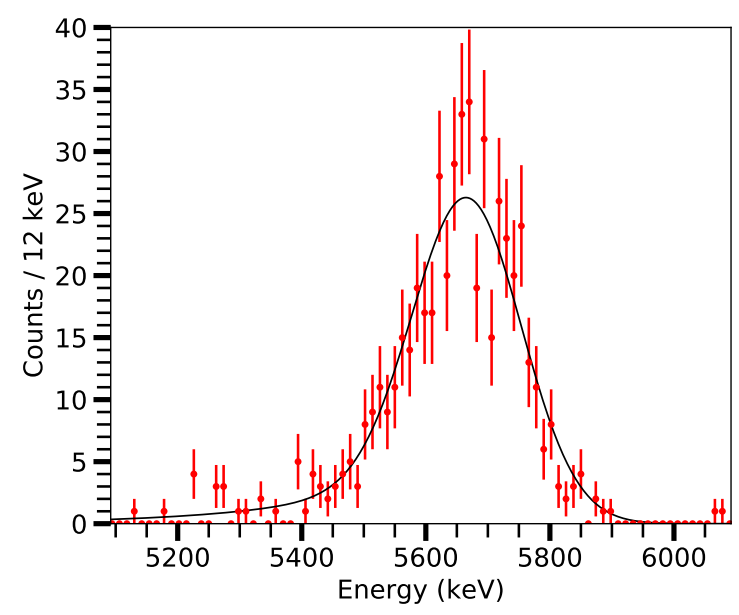

FIG. 6. The $\alpha$-decay energy spectrum gated on the $129-\mathrm{keV}$ transition, plotted together with a fit to the experimental data $\left[E_{\alpha}=\right.$ $5670(51) \mathrm{keV}]$.

and 6.5 MeV. Both $\gamma$-gated spectra were corrected by the detection efficiency and by the total conversion coefficient calculated using BrIcc [24]. The 202-keV transition was not included because it is unplaced in the decay scheme while the 141- and 144-keV transitions were not included to avoid double counting of the $\alpha$ particles since they feed the 129$\mathrm{keV}$ level. Furthermore, the 104-keV transition was not used for gating, because it may also originate from the decay of the $\left(7^{+}\right)$state in ${ }^{182} \mathrm{Au}$ [25]. To account for this feeding, the $\alpha$-energy spectrum gated on the $129-\mathrm{keV}$ transition was corrected by the total intensity of the $104-\mathrm{keV}$ transition, $32(3) \%$, from the ${ }^{182} \mathrm{Hg} \beta$-decay studies [22]. From this comparison, the $\gamma$-gated- $\alpha$ counts can reproduce $105(7) \%$ of the total number of $\alpha$ counts in the single- $\alpha$ energy spectrum, suggesting that the vast majority of the registered $\alpha$ decays originates from the $\left(2^{-}\right)$state (see Sec. IV A).

Based on the measured $\alpha$-particle energies with a gate on the 129-keV $\gamma$-ray transition, the energy of the $\alpha$ decay feeding the $129-\mathrm{keV}$ level was determined to be $E_{\alpha}=5670(51)$ $\mathrm{keV}$ (see Fig. 6) and it corresponds to the $Q_{\alpha \text {,tot }}=Q_{\alpha}+$ $E_{\gamma}=5924(52) \mathrm{keV}$. Because of limited statistics, it was not possible to fit the $\alpha$ energies feeding other states. The extracted $Q_{\alpha, \text { tot }}$ and the atomic masses of ${ }^{4} \mathrm{He}$ and ${ }^{182} \mathrm{Au}[26,27]$ allowed us to calculate the atomic mass of the ${ }^{186} \mathrm{Tl}\left(2^{-}\right)$state $185978582(60) \mu \mathrm{u}$ and to compare it with the atomic mass of the ${ }^{186} \mathrm{Tl}\left(7^{(+)}\right)$state $(185978664.2(67) \mu \mathrm{u}[27,28])$. Our analysis indicates that the $\left(2^{-}\right)$state is the ground state and the $7^{(+)}$level has an excitation energy of 77(56) keV. Based on our result and the $\alpha$-particle energies [6,12], it was also possible to fix the relative positions of the $\alpha$-decaying states in ${ }^{190} \mathrm{Bi}$ with the $\left(10^{-}\right)$level being $182(57) \mathrm{keV}$ above the $\left(3^{+}\right)$ ground state.

\section{B. Decay of the $10^{(-)}$state}

The single $\gamma$-ray energy spectrum (Fig. 7) shows the 374$\mathrm{keV}$ transition previously assigned to the $10^{(-)} \rightarrow 7^{(+)}$decay [13]. By using $\gamma-\gamma$ coincidences, another decay cascade deexciting through an $18-\mathrm{keV}$ transition was established. Furthermore, a $\beta$-decay channel of the $10^{(-)}$state was identified.

The 267-keV $\gamma$-ray transition has been observed in coincidence with thallium $\mathrm{K}_{\alpha} \mathrm{x}$ rays (Fig. 8), as well as in coincidence with a $\gamma$-ray energy gate set between 89 and $90 \mathrm{keV}$ (Fig. 9). These results are consistent with the $\alpha$ decay study of ${ }^{190} \mathrm{Bi}$, where the $267-\mathrm{keV} \gamma$-ray transition

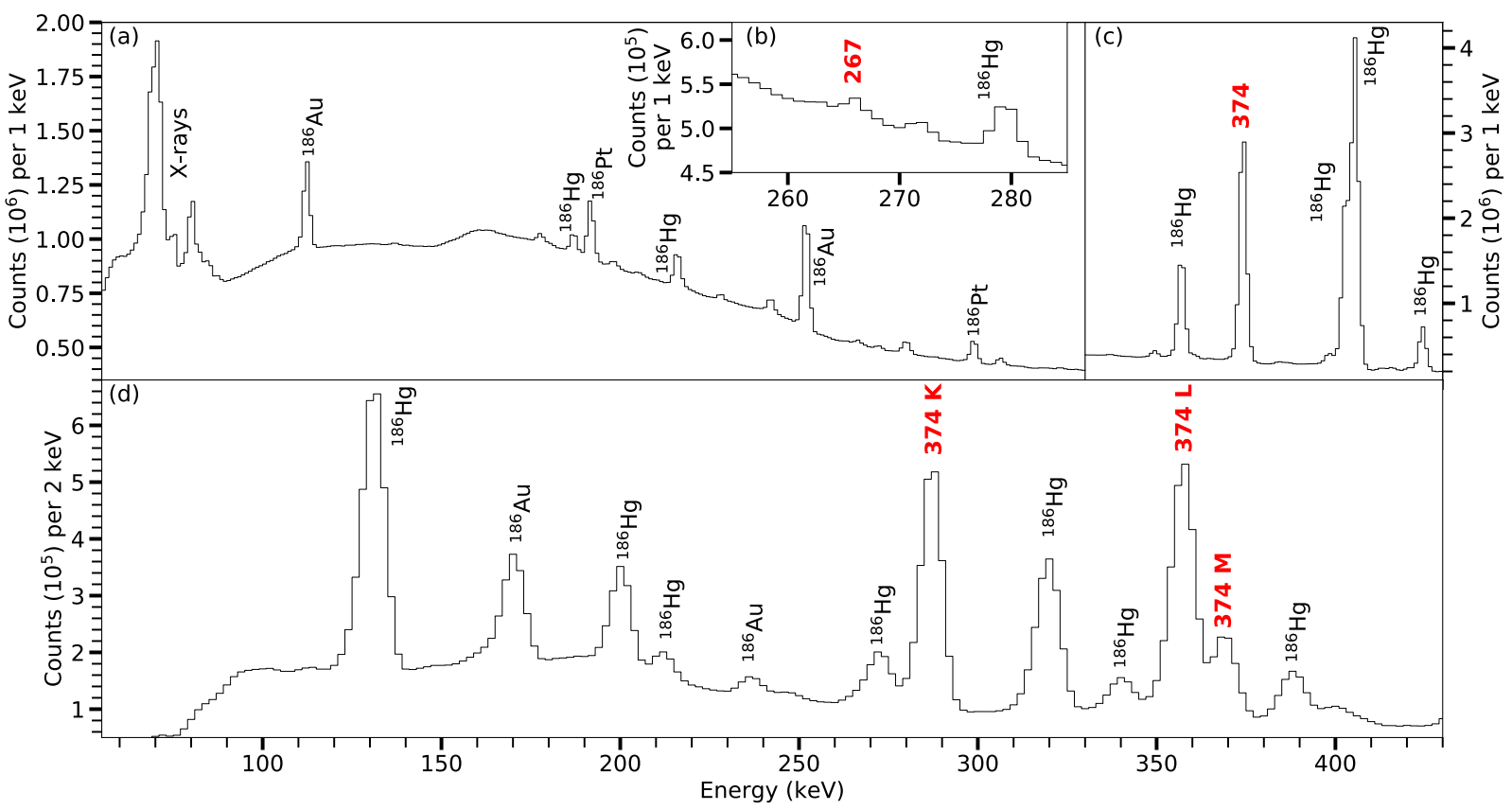

FIG. 7. Portions of the single- $\gamma$ [(a)-(c)] and single-electron (d) energy spectra. The transitions from the decay of the ${ }^{186} \mathrm{Tl}\left(10^{-}\right)$isomer are labeled in red. Other strong peaks are labeled with the symbol of the nucleus they originate from. Note different scales on the $y$ axes of each panel. 


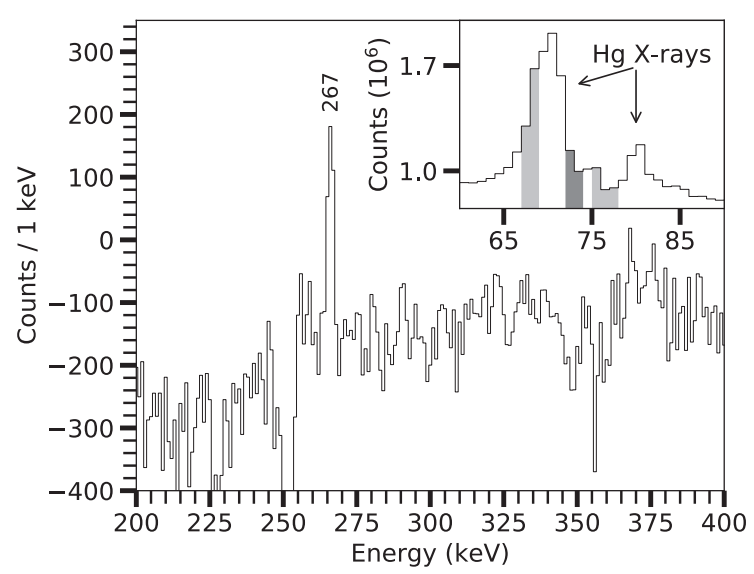

FIG. 8. The background-subtracted $\gamma-\gamma$ spectrum gated on the thallium $\mathrm{x}$ rays. A negative background is related to much higher intensity of the $\mathrm{Hg} \mathrm{K} \mathrm{K}_{\alpha} \mathrm{x}$ rays. Two dips at 251 and $356 \mathrm{keV}$ are related to the subtraction of the strong $\gamma$ rays from the decay of ${ }^{186} \mathrm{Hg}$ to ${ }^{186} \mathrm{Au}$ and ${ }^{186} \mathrm{Tl}$ to ${ }^{186} \mathrm{Hg}$, respectively. In the inset, a portion of the single- $\gamma$ energy spectrum with the gate region (dark gray) and the background region (light gray) used to create the $\gamma$-ray energy spectrum shown is plotted.

was proposed to de-excite the $(x+356)-\mathrm{keV}$ level to the $(x+89.5(4))-\mathrm{keV}$ state $[6,12]$. These observations also imply that the $(x+374)-\mathrm{keV}$ level de-excites through an $18-\mathrm{keV}$ transition to the $(x+356)-\mathrm{keV}$ state. In the present work, the other $\gamma$ rays de-exciting the $(x+356)-\mathrm{keV}$ level [6] were not observed; the 75-keV transition overlaps with the background lead $\mathrm{K}_{\alpha} \mathrm{x}$ rays, while the 281 - and $356-\mathrm{keV}$ transitions overlap with strong $\gamma$ rays in ${ }^{186} \mathrm{Hg}$. The proposed decay scheme is presented in Fig. 10.

The $\gamma$-ray intensities of the 267- and 374-keV transitions were extracted from the single $\gamma$-ray energy spectrum (see Fig. 7 and Table II). To estimate the total intensity of the 18-keV transition, the spectrum shown in Fig. 6(c) of Ref. [6]

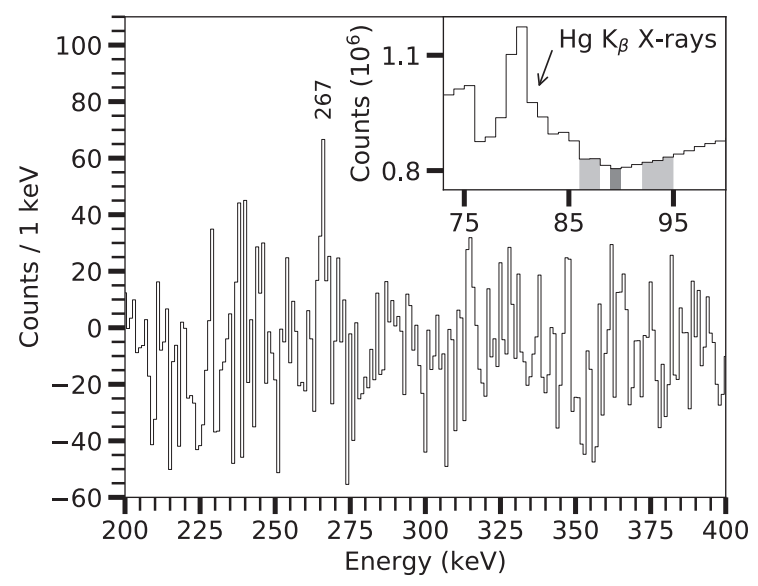

FIG. 9. The background-subtracted $\gamma-\gamma$ spectrum gated on the $\gamma$ rays between 89 and $90 \mathrm{keV}$. In the inset, a portion of the single- $\gamma$ energy spectrum with the gate region (dark gray) and the background region (light gray) used to create the $\gamma$-ray energy spectrum shown, is plotted.

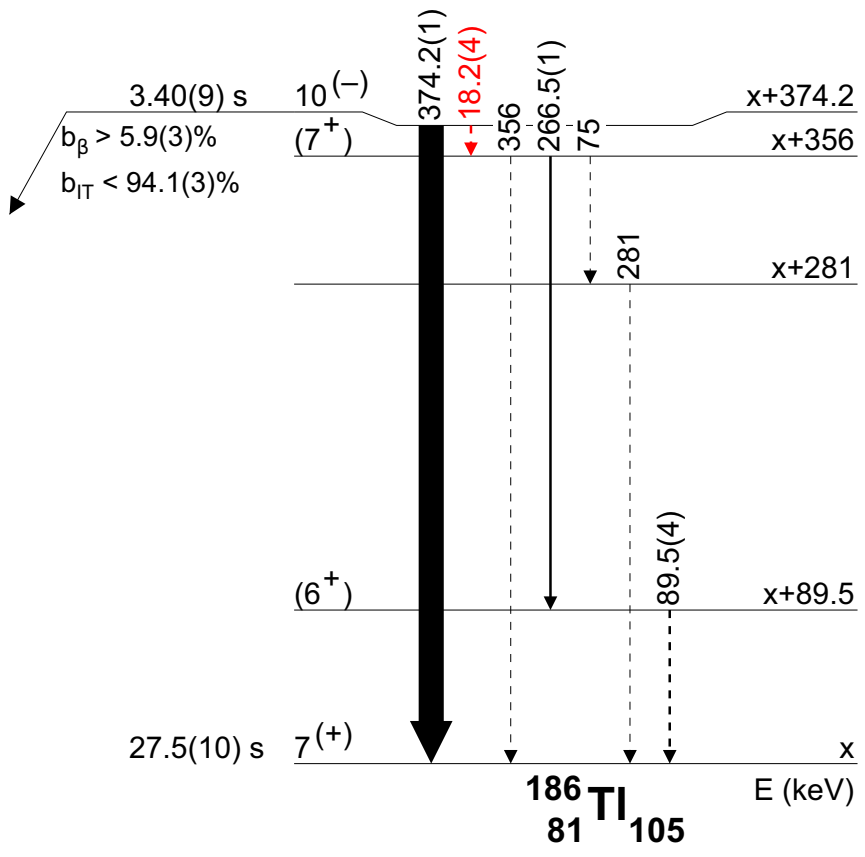

FIG. 10. The decay scheme of the isomeric $10^{(-)}$state in ${ }^{186} \mathrm{Tl}$ obtained from our analysis. The transitions marked with the dashed lines have not been observed, but they are known from the $\alpha$-decay studies $[6,12]$. The existence of the $18-\mathrm{keV}$ transition (indicated by the dashed red line) is suggested by the observation of the $267-\mathrm{keV}$ transition in our study. The spin assignments come from Refs. [2,6,12] except for the $(x+356)-\mathrm{keV}$ state; see text for details. The half-life of the $10^{(-)}$state comes from our analysis, while the half-life of the $7^{(+)}$state is taken from Ref. [29]. From our analysis, $x=77(56) \mathrm{keV}$.

was analyzed. The peaks at 267,281 , and $356 \mathrm{keV}$ contained $\approx 60$ counts, $\approx 20$ counts, and $\approx 54$ counts, respectively. The detection efficiencies for the 281- and 356-keV transitions were $98 \%$ and $86 \%$ relative to the efficiency for the $267-\mathrm{keV}$ transition, respectively, following the calibration provided in Ref. [30]. To estimate the contribution from the internal conversion, all three transitions were considered to be pure $M 1$ or pure $E 2$, which resulted in the total feeding of the $(x+356)-\mathrm{keV}$ state being equal to $1.8(2) \%$ and $1.4(2) \%$, respectively. Since the true transition multipolarities are not

TABLE II. The relative intensities of the $\gamma$-ray transitions assigned to the internal decay of the $10^{(-)}$state in ${ }^{186} \mathrm{Tl}$.

\begin{tabular}{lcccc}
\hline \hline$E_{\gamma}(\mathrm{keV})$ & $I_{\gamma}^{\text {rel }}$ & Multipolarity & $\alpha_{\mathrm{tot}}$ & $I_{\mathrm{tot}}^{\mathrm{rel}}$ \\
\hline $18.2(4)$ & $4.8(14) \times 10^{-7 \mathrm{a}}$ & $E 3$ & $3.3(5) \times 10^{6 \mathrm{~b}}$ & $1.6(4)^{\mathrm{a}}$ \\
$266.5(1)$ & $0.55(3)$ & $M 1+E 2$ & $0.35(20)^{\mathrm{c}}$ & $0.74(12)$ \\
$374.2(1)$ & 100 & $E 3$ & $0.249(4)^{\mathrm{b}}$ & $124.9(4)$
\end{tabular}

a Estimated based on the data presented in Ref. [6]; see text for details.

${ }^{\mathrm{b}}$ Calculated using BrIcc [24] assuming given multipolarity.

${ }^{\mathrm{c}}$ Average value of conversion coefficient for pure $M 1$ and pure $E 2$ transition, calculated using BrIcc [24]. 


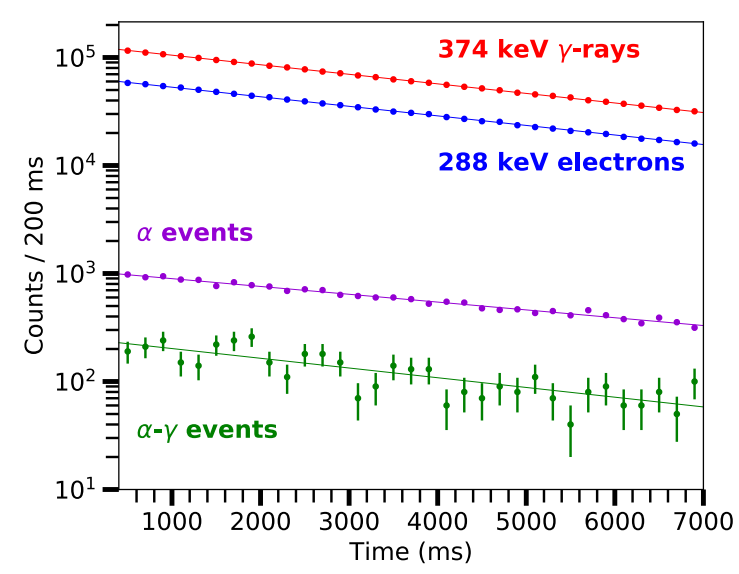

FIG. 11. The decay curves of the ${ }^{186} \mathrm{Tl}\left(10^{(-)}\right)$state $\left[T_{1 / 2}\left(10^{(-)}\right)=3.40(9) \mathrm{s}\right]$ fitted to the $374-\mathrm{keV} \gamma$ ray (red) and to the $288-\mathrm{keV}$ electrons ( $\mathrm{K}$ conversion electrons of the $374-\mathrm{keV}$ transition; blue), as well as decay curves of the ${ }^{186} \mathrm{Tl}\left(2^{-}\right)$state $\left[T_{1 / 2}\left(2^{-}\right)=3.4_{-0.4}^{+0.5} \mathrm{~s}\right]$ fitted to the $\alpha-\gamma$ events (green, multiplied by a factor 10 for the presentation) and of the $\alpha$ particles in between 5.4 and 6.5 MeV [purple, $T_{1 / 2}=4.16(10) \mathrm{s}$ ].

known, 1.6(4)\% was adopted as the total intensity of the $18-\mathrm{keV}$ transition.

To determine the possible $\beta$-decay branch from the $10^{(-)}$ state in ${ }^{186} \mathrm{Tl}$, the feeding to the known high-spin states $(\geqslant 9)$ in ${ }^{186} \mathrm{Hg}$ was analyzed. It was assumed that both direct and indirect feeding of these states originate only from the decay of the ${ }^{186} \mathrm{Tl} 10^{(-)}$state. In total, six high-spin states in ${ }^{186} \mathrm{Hg}$ have been observed in our study: the $10^{+}$state at 2078.1 $\mathrm{keV}$, the $\left(9^{-}\right)$at $2427.6 \mathrm{keV}$, the (9) at $2573.8 \mathrm{keV}$, the $12^{+}$ at $2620.1 \mathrm{keV}$, the $\left(10^{+}\right)$at $2636.4 \mathrm{keV}$, and the $10^{+}$at $2833.6 \mathrm{keV}$. By comparing the feeding to these states with the isomeric decay, a $\beta$ branching equal to 5.9(3)\% was extracted. It should be noted that the presented method allows us to estimate only the lower limit for the $\beta$ branching since we observed decays of several states with the unknown spins [14], which can be also fed through the decay of the $10^{(-)}$state.

\section{Half-lives of the $\left(2^{-}\right)$and $10^{(-)}$states}

The half-life of the $10^{(-)}$state was obtained by simultaneously fitting an exponential function to the number of the $\gamma$ rays and the $\mathrm{K}$ conversion electrons stemming from the 374-keV transition (Fig. 7) plotted as a function of time (Fig. 11). The fitting range was set from 400 to $7000 \mathrm{~ms}$ after the PP and the likelihood function was built assuming that all the points are following a Poisson distribution. The results of the fit are presented in Fig. 11 (red and blue curves). The obtained value of $T_{1 / 2}\left(10^{(-)}\right)=3.40(9) \mathrm{s}$ is in agreement with $4.5_{-1.5}^{+1.0}$ s reported in Ref. [31], 4.5(13) s reported in Ref. [32], and 3(1) s reported in Ref. [33]; however, it is more than $2 \sigma$ away from the 2.9(2) s reported in Ref. [13].

The half-life of the $\left(2^{-}\right)$state was obtained by fitting an exponential function to the $\alpha-\gamma$ events plotted as a function of time. The energy gates were set on all the $\gamma$ rays placed in the decay scheme of the ${ }^{186} \mathrm{Tl}\left(2^{-}\right)$state, with the exception of the $104-\mathrm{keV}$ transition, as it might also originate from the decay of the $7^{(+)}$state (see Sec. IV A). The fitting range and the method are the same as for the half-life of the $10^{(-)}$ state. The results of the fit are presented in Fig. 11 (green curve). The extracted half-life is equal to $3.4_{-0.4}^{+0.5} \mathrm{~s}$. This value was compared to the results obtained from the fitting of the exponential function to the time distribution of the $\alpha$ particles with energies between 5.4 and $6.5 \mathrm{MeV}$ (Fig. 11, purple curve). The extracted half-life of $4.16(10) \mathrm{s}$ is larger, but in agreement within $2 \sigma$. The discrepancy might be explained by a small admixture of the $\alpha$ particles from the long-lived ${ }^{186} \mathrm{Tl}\left(7^{(+)}\right)$state $\left(T_{1 / 2}=27.5(10) \mathrm{s}[29]\right)$, and thus we adopted $T_{1 / 2}=3.4_{-0.4}^{+0.5} \mathrm{~s}$ as the half-life of the $\left(2^{-}\right)$state. However, we note that the expected admixture should be small, which was presented by comparing the number of single- $\alpha$ and $\alpha-\gamma$ events (see Sec. IV A).

\section{DISCUSSION}

\section{A. $\alpha$ decay of the $\left(2^{-}\right)$state}

Because of the limited $\alpha$-energy resolution and the inability to extract the $b_{\alpha}$ value from the current data set, it was not possible to determine the reduced $\alpha$-decay widths. Nevertheless, some conclusions can be drawn from the presented results.

The population of the low-spin states in ${ }^{182} \mathrm{Au}$ is consistent with the pattern observed in the $\alpha$-decay studies of the neighboring isotope ${ }^{184} \mathrm{Tl}$, where the low-spin state has a higher $\alpha$-decay branching than the high-spin state. In ${ }^{184} \mathrm{Tl}$, $b_{\alpha}\left(2^{-}\right)=1.22(30) \%$, compared to $0.47(6) \%$ for the $7^{(+)}$state and $0.089(19) \%$ for the $10^{(-)}$state [9].

In-beam studies [25] revealed the existence of two bands in ${ }^{182} \mathrm{Au}$ built on top of isomeric states with proposed spins and parities of $\left(6^{+}\right)$and $\left(10^{-}\right)$. Thus, it cannot be excluded that the $10^{(-)}$state in ${ }^{186} \mathrm{Tl}$ is $\alpha$ decaying directly to the $\left(10^{-}\right)$isomer in ${ }^{182} \mathrm{Au}$, without emission of a $\gamma$ ray.

In the case of the possible $\alpha$ decay of the ${ }^{186} \mathrm{Tl}\left(7^{(+)}\right)$, it could decay to the ${ }^{182} \mathrm{Au}\left(7^{+}\right)$state and then de-excite by emission of a 104-keV $\gamma$ ray to the $\left(6^{+}\right)$isomeric state. However, a $\gamma$ ray with the same energy is emitted from the decay of the $129-\mathrm{keV}$ state in ${ }^{182} \mathrm{Au}$, known from the $\beta$-decay study of ${ }^{182} \mathrm{Hg}$ [22]. The $\gamma$-intensity ratio of 104 to $129 \mathrm{keV}$ obtained from this work $\left(0.24_{-0.04}^{+0.05}\right)$ is in agreement with the ratio extracted from the $\beta$-decay study $(0.23(2)$ [22]) and suggests that the majority of the $104-\mathrm{keV}$ transition originates from the $\alpha$ decay of the ${ }^{186} \mathrm{Tl}\left(2^{-}\right)$state. However, it should be noted that the 104-keV transition (from the 129-keV level to the $25-\mathrm{keV}$ level) is known to be $E 1$ [22] with a total theoretical conversion coefficient $\alpha_{\text {tot }}(E 1)=0.376(11)$ [24], while the $104-\mathrm{keV}\left(7^{+}\right) \rightarrow\left(6^{+}\right)$transition would be a mixed $M 1 / E 2$ transition with $\alpha_{\text {tot }}(E 2)=4.42(19)$ and $\alpha_{\text {tot }}(M 1)=$ $6.49(21)$ [24]. Thus, it cannot be excluded that the ${ }^{186} \mathrm{Tl}\left(7^{(+)}\right)$ state has an $\alpha$-decay branch. This would be consistent with the observed difference between half-lives obtained from the $\alpha$ particles and $\alpha-\gamma$ events; however, the 5(7)\% excess intensity of $\alpha-\gamma$ events compared to the single- $\alpha$ events indicates that this branching should be small. 
TABLE III. The retardation factors for $M 2$ and $E 3$ transitions in ${ }^{184,186,188} \mathrm{Tl}$ isotopes. Data for ${ }^{186} \mathrm{Tl}$ are extracted from this work, while those for the other isotopes are taken from Refs. [8,35]. The retardation factors for ${ }^{186} \mathrm{Tl}$ should be treated as a lower limit since the $\beta$-decay branching ratio is given only as a lower limit.

\begin{tabular}{lccc}
\hline \hline Isotope & $E_{\gamma}(\mathrm{keV})$ & Multipolarity & $F_{w}$ \\
\hline${ }^{184} \mathrm{Tl}$ & 61 & $M 2$ & $3.84(16) \times 10^{4}$ \\
${ }^{184} \mathrm{Tl}$ & 186 & $E 3$ & $486(115)$ \\
${ }^{184} \mathrm{Tl}$ & 506 & $E 3$ & $984(38)$ \\
${ }^{186} \mathrm{Tl}$ & $18.2(4)$ & $E 3$ & $1053(347)$ \\
${ }^{186} \mathrm{Tl}$ & $374.2(1)$ & $E 3$ & $7934(215)$ \\
${ }^{188} \mathrm{Tl}$ & 268.8 & $M 2$ & $1.93(19) \times 10^{5}$ \\
\hline \hline
\end{tabular}

\section{B. Decay of the $10^{(-)}$state}

The isomeric character of the 374-keV state suggests that $M 2$ or E3 are possible multipolarities for the $18-\mathrm{keV}$ transition. For any higher multipolarity, the intensity of the $18-\mathrm{keV}$ transition would be negligible compared to the 374-keV E3 transition. Retardation factors $F_{w}$, which are defined as a ratio of the Weisskopf estimate and the experimental transition strength, favor $E 3$ multipolarity for the $18-\mathrm{keV}$ compared to $M 2$. The latter would lead to $F_{w}=3.5(10) \times 10^{7}$, which is at least two orders of magnitude higher compared to the similar transitions in the neighboring isotopes (see Table III). Thus, the $18-\mathrm{keV}$ transition is proposed to have multipolarity E3 and, consequently, the spin $\left(7^{+}\right)$has been tentatively assigned to the state at $x+356 \mathrm{keV}$. This spin assignment is also supported by the $\alpha$-decay study of ${ }^{188,190} \mathrm{Bi}$ to ${ }^{184,186} \mathrm{Tl}$ [6]. A reduced $\alpha$-decay width to the $(x+356)-\mathrm{keV}$ level in ${ }^{186} \mathrm{Tl}$ $\left[\delta_{\alpha}^{2}=0.11(3) \mathrm{keV}\right]$ obtained in Ref. [6] is similar to the reduced $\alpha$-decay width feeding the $320-\mathrm{keV}$ level in ${ }^{184} \mathrm{Tl}$ $\left[\delta_{\alpha}^{2}=0.16(6) \mathrm{keV}\right]$, which has been proposed to be the $\left(7_{2}^{+}\right)$ state; see Fig. 12.

The measurements of the magnetic moments indicated that ${ }^{186} \mathrm{Tl}\left(7_{1}^{+}\right)$is dominated by the $\left[\pi s_{1 / 2} \otimes \nu i_{13 / 2}\right]_{7^{+}}$configuration, while ${ }^{184} \mathrm{Tl}\left(7_{1}^{+}\right)$should have a $\approx 20 \%$ admixture from a $\left[\pi d_{3 / 2} \otimes v i_{13 / 2}\right]_{7^{+}}$configuration $[3,36]$. This admixture can explain the difference in the retardation factors of the 506and 374-keV E3 transitions (Table III). In both ${ }^{184} \mathrm{Tl}$ and ${ }^{186} \mathrm{Tl}$, the dominant configuration of the $10^{-}$intruder state was determined from the magnetic moment measurements to be $\left[\pi h_{9 / 2} \otimes v i_{13 / 2}\right]_{10^{-}}[2,3]$ and from a single-particle approach, the transition between the $\pi h_{9 / 2}$ and $\pi d_{3 / 2}$ requires a smaller
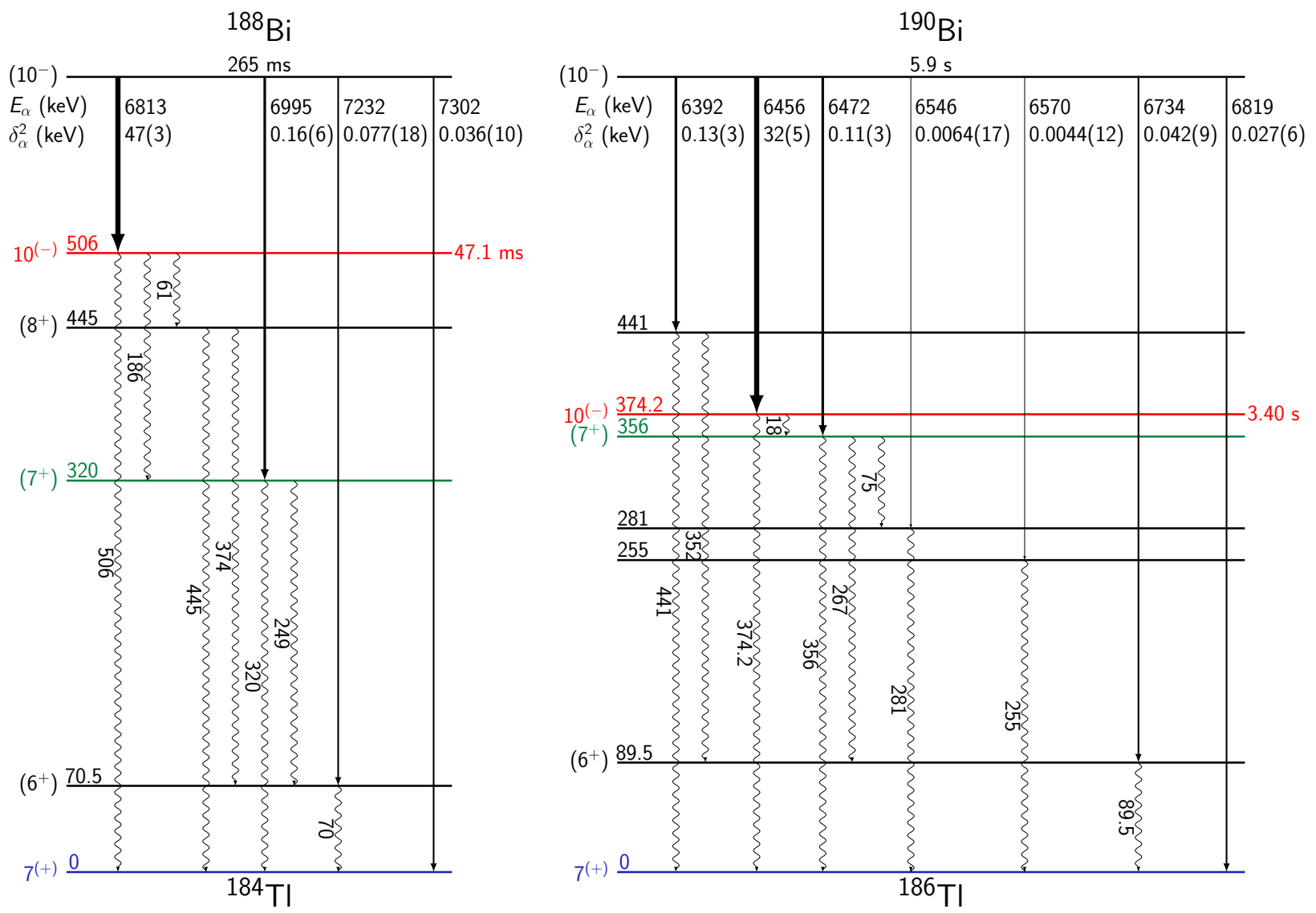

FIG. 12. Systematic information from the $\alpha$ - and isomeric decay studies in ${ }^{184,186} \mathrm{Tl}$. Next to each $\alpha$ transition, the energies and the reduced decay widths calculated using the Rasmussen formalism [34] are presented. The color code represents the main underlying proton singleparticle configuration as interpreted from magnetic moment measurements and systematics configurations [2,3,8] with the states involving the $\pi s_{1 / 2}$ orbital plotted in blue, the $\pi d_{3 / 2}$ orbital plotted in green, and the $\pi h_{9 / 2}$ orbital plotted in red. The energies of the excited states in thallium isotopes are shifted to set the $7_{1}^{+}$states at 0 . Experimental data are taken from our analysis and Refs. $[2,3,6,8]$. 
angular momentum change $(\Delta \ell=3)$ compared to the transition between the $\pi h_{9 / 2}$ and $\pi s_{1 / 2}(\Delta \ell=5)$. This change was proposed in Ref. [8] to be the reason for the $374-\mathrm{keV}$ transition in ${ }^{186} \mathrm{Tl}$ being retarded by an order of magnitude more, relative to the $506-\mathrm{keV}$ transition in ${ }^{184} \mathrm{Tl}$. In contrast, the retardations of the $10^{-} \rightarrow 7_{2}^{+}$transitions in ${ }^{184} \mathrm{Tl}$ and ${ }^{186} \mathrm{Tl}$ are within the factor of 2 similar (note the large experimental uncertainties). This can be explained as due to a substantial contribution of the proton $d_{3 / 2}$ component in these $7_{2}^{+}$states.

\section{CONCLUSIONS}

The decay of the long-lived states in ${ }^{186} \mathrm{Tl}$ was studied at ISOLDE, CERN. The existence of the $\left(2^{-}\right)$state was confirmed and its half-life of $3.4_{-0.4}^{+0.5} \mathrm{~s}$ was determined for the first time through the observation of its $\alpha$ decay. Six $\gamma$-ray transitions were measured in coincidence with the $\alpha$ decay of ${ }^{186} \mathrm{Tl}$, which allowed the construction of an $\alpha$-decay scheme feeding the levels in ${ }^{182} \mathrm{Au}$.

Based on the $\alpha$-decay energy, the $7^{(+)}$state in ${ }^{186} \mathrm{Tl}$ was positioned $77(56) \mathrm{keV}$ above the $\left(2^{-}\right)$ground state and the $\left(10^{-}\right)$level in ${ }^{190} \mathrm{Bi}$ was placed $182(57) \mathrm{keV}$ above the $\left(3^{+}\right)$ ground state. The decay scheme of the ${ }^{186} \mathrm{Tl}\left(10^{(-)}\right)$state was extended, the half-life of 3.40(9) s was measured, and a limit for the $\beta$-decay branching ratio has been deduced. The more detailed internal decay pattern observed for the $10^{(-)}$state is consistent with the "intruder" origin of the isomer and follows a clear trend throughout the thallium isotopic chain. Based on the $E 3$ retardation factors for the $10^{(-)} \rightarrow 7^{(+)}$transitions, as well as additional information from bismuth $\alpha$-decay studies, the $(x+356)-\mathrm{keV}$ state was tentatively assigned with $\left(7^{+}\right)$ spin. A comparison with a neighboring isotope of ${ }^{184} \mathrm{Tl}$ indicated significant differences in the structure of the $7^{+}$states.

\section{ACKNOWLEDGMENTS}

We acknowledge the support of the ISOLDE Collaboration and technical teams. This project has received funding from the European Unions Horizon 2020 research and innovation programme Grant Agreements No. 654002 (ENSAR2) and No. 665779. This work has been funded by FWO-Vlaanderen (Belgium), by GOA/2015/010 (BOF KU Leuven), by the Interuniversity Attraction Poles Programme initiated by the Belgian Science Policy Office (BriX network P7/12), by the Slovak Research and Development Agency (Contract No. APVV-18-0268), by the Slovak Grant Agency VEGA (Contract No. 1/0532/17), by the Spanish Research Council under Contracts No. FPA201564969-P, No. FPA2015-65035-P, No. FPA2017-87568-P, and No. RTI2018-098868-B-I00 (MINECO/FEDER, UE), by the Spanish Ministry of Science with Grant No. FPA201783946-C2-1-P (MCIU/AEI/FEDER), by Technology Facilities Council (STFC) of the UK Grant No. ST/R004056/1, by the German BMBF under Contract No. 05P18PKCIA, by the Romanian IFA project CERN-RO/ISOLDE, by the National Science Centre (Poland) Grant No. 2015/18/M/ST2/00523, and by the Academy of Finland (Finland) Grant No. 307685.
[1] K. Heyde and J. L. Wood, Rev. Mod. Phys. 83, 1467 (2011).

[2] A. E. Barzakh, L. K. Batist, D. V. Fedorov, V. S. Ivanov, K. A. Mezilev, P. L. Molkanov, F. V. Moroz, S. Y. Orlov, V. N. Panteleev, and Y. M. Volkov, Phys. Rev. C 88, 024315 (2013).

[3] A. E. Barzakh, A. N. Andreyev, T. E. Cocolios, R. P. de Groote, D. V. Fedorov, V. N. Fedosseev, R. Ferrer, D. A. Fink, L. Ghys, M. Huyse, U. Köster, J. Lane, V. Liberati, K. M. Lynch, B. A. Marsh, P. L. Molkanov, T. J. Procter, E. Rapisarda, S. Rothe, K. Sandhu, M. D. Seliverstov, A. M. Sjödin, C. Van Beveren, P. Van Duppen, M. Venhart, and M. Veselský, Phys. Rev. C 95, 014324 (2017).

[4] B. A. Marsh, T. Day Goodacre, S. Sels, Y. Tsunoda, B. Andel, A. N. Andreyev, N. A. Althubiti, D. Atanasov, A. E. Barzakh, J. Billowes, K. Blaum, T. E. Cocolios, J. G. Cubiss, J. Dobaczewski, G. J. Farooq-Smith, D. V. Fedorov, V. N. Fedosseev, K. T. Flanagan, L. P. Gaffney, L. Ghys, M. Huyse, S. Kreim, D. Lunney, K. M. Lynch, V. Manea, Y. Martinez Palenzuela, P. L. Molkanov, T. Otsuka, A. Pastore, M. Rosenbusch, R. E. Rossel, S. Rothe, L. Schweikhard, M. D. Seliverstov, P. Spagnoletti, C. Van Beveren, P. Van Duppen, M. Veinhard, E. Verstraelen, A. Welker, K. Wendt, F. Wienholtz, R. N. Wolf, A. Zadvornaya, and K. Zuber, Nat. Phys. 14, 1163 (2018).

[5] S. Sels, T. Day Goodacre, B. A. Marsh, A. Pastore, W. Ryssens, Y. Tsunoda, N. Althubiti, B. Andel, A. N. Andreyev, D. Atanasov, A. E. Barzakh, M. Bender, J. Billowes, K. Blaum, T. E. Cocolios, J. G. Cubiss, J. Dobaczewski, G. J. Farooq-
Smith, D. V. Fedorov, V. N. Fedosseev, K. T. Flanagan, L. P. Gaffney, L. Ghys, P.-H. Heenen, M. Huyse, S. Kreim, D. Lunney, K. M. Lynch, V. Manea, Y. Martinez Palenzuela, T. M. Medonca, P. L. Molkanov, T. Otsuka, J. P. Ramos, R. E. Rossel, S. Rothe, L. Schweikhard, M. D. Seliverstov, P. Spagnoletti, C. Van Beveren, P. Van Duppen, M. Veinhard, E. Verstraelen, A. Welker, K. Wendt, F. Wienholtz, R. N. Wolf, and A. Zadvornaya, Phys. Rev. C 99, 044306 (2019).

[6] A. N. Andreyev, D. Ackermann, S. Antalic, H. J. Boardman, P. Cagarda, J. Gerl, F. P. Heßberger, S. Hofmann, M. Huyse, D. Karlgren, A. Keenan, H. Kettunen, A. Kleinböhl, B. Kindler, I. Kojouharov, A. Lavrentiev, C. D. O'Leary, M. Leino, B. Lommel, M. Matos, C. J. Moore, G. Münzenberg, R. D. Page, S. Reshitko, S. Saro, H. Schaffner, C. Schlegel, M. J. Taylor, K. Van de Vel, P. Van Duppen, L. Weissman, and K. Heyde, Eur. Phys. J. A 18, 39 (2003).

[7] A. N. Andreyev, D. Ackermann, F. P. Heßberger, S. Hofmann, M. Huyse, I. Kojouharov, B. Kindler, B. Lommel, G. Münzenberg, R. D. Page, K. Van de Vel, P. Van Duppen, and K. Heyde, Eur. Phys. J. A 18, 55 (2003).

[8] C. Van Beveren, A. N. Andreyev, A. E. Barzakh, T. E. Cocolios, D. Fedorov, V. N. Fedosseev, R. Ferrer, M. Huyse, U. Köster, J. Lane, V. Liberati, K. M. Lynch, B. A. Marsh, T. J. Procter, D. Radulov, E. Rapisarda, K. Sandhu, M. D. Seliverstov, P. Van Duppen, M. Venhart, and M. Veselsky, Phys. Rev. C 92, 014325 (2015)

[9] C. Van Beveren, A. N. Andreyev, A. E. Barzakh, T. E. Cocolios, R. P. De Groote, D. Fedorov, V. N. Fedosseev, R. Ferrer, 
L. Ghys, M. Huyse, U. Köster, J. Lane, V. Liberati, K. M. Lynch, B. A. Marsh, P. L. Molkanov, T. J. Procter, E. Rapisarda, K. Sandhu, M. D. Seliverstov, P. Van Duppen, M. Venhart, and M. Veselský, J. Phys. G: Nucl. Part. Phys. 43, 025102 (2016).

[10] E. Rapisarda, A. N. Andreyev, S. Antalic, A. Barzakh, T. E. Cocolios, I. G. Darby, R. De Groote, H. De Witte, J. Diriken, J. Elseviers, D. Fedorov, V. N. Fedosseev, R. Ferrer, M. Huyse, Z. Kalaninová, U. Köster, J. Lane, V. Liberati, K. M. Lynch, B. A. Marsh, P. L. Molkanov, D. Pauwels, T. J. Procter, D. Radulov, K. Sandhu, M. D. Seliverstov, C. Van Beveren, P. Van den Bergh, P. Van Duppen, M. Venhart, M. Veselský, and K. Wrzosek-Lipska, J. Phys. G: Nucl. Part. Phys. 44, 074001 (2017).

[11] K. Wrzosek-Lipska, K. Rezynkina, N. Bree, M. Zielińska, L. P. Gaffney, A. Petts, A. Andreyev, B. Bastin, M. Bender, A. Blazhev, B. Bruyneel, P. A. Butler, M. P. Carpenter, J. Cederkäll, E. Clément, T. E. Cocolios, A. N. Deacon, J. Diriken, A. Ekström, C. Fitzpatrick, L. M. Fraile, C. Fransen, S. J. Freeman, J. E. García-Ramos, K. Geibel, R. Gernhäuser, T. Grahn, M. Guttormsen, B. Hadinia, K. Hadyńska-Klęk, M. Hass, P. H. Heenen, R. D. Herzberg, H. Hess, K. Heyde, M. Huyse, O. Ivanov, D. G. Jenkins, R. Julin, N. Kesteloot, T. Kröll, R. Krücken, A. C. Larsen, R. Lutter, P. Marley, P. J. Napiorkowski, R. Orlandi, R. D. Page, J. Pakarinen, N. Patronis, P. J. Peura, E. Piselli, L. Próchniak, P. Rahkila, E. Rapisarda, P. Reiter, A. P. Robinson, M. Scheck, S. Siem, K. Singh Chakkal, J. F. Smith, J. Srebrny, I. Stefanescu, G. M. Tveten, P. Van Duppen, J. Van de Walle, D. Voulot, N. Warr, A. Wiens, and J. L. Wood, Eur. Phys. J. A 55, 130 (2019).

[12] P. Van Duppen, P. Decrock, P. Dendooven, M. Huyse, G. Reusen, and J. Wauters, Nucl. Phys. A 529, 268 (1991).

[13] A. J. Kreiner, C. Baktash, G. Garcia Bermudez, and M. A. J. Mariscotti, Phys. Rev. Lett. 47, 1709 (1981).

[14] M. Stryjczyk et al., $\beta$-decay studies of ${ }^{182,184,186} \mathrm{Tl}$ (unpublished).

[15] V. Fedosseev, K. Chrysalidis, T. D. Goodacre, B. Marsh, S. Rothe, C. Seiffert, and K. Wendt, J. Phys. G: Nucl. Part. Phys. 44, 084006 (2017).

[16] R. Catherall, W. Andreazza, M. Breitenfeldt, A. Dorsival, G. J. Focker, T. P. Gharsa, T. J. Giles, J.-L. Grenard, F. Locci, P. Martins, S. Marzari, J. Schipper, A. Shornikov, and T. Stora, J. Phys. G: Nucl. Part. Phys. 44, 094002 (2017).

[17] http://isolde-ids.web.cern.ch/isolde-ids/

[18] P. Papadakis, D. M. Cox, G. G. O’Neill, M. J. G. Borge, P. A. Butler, L. P. Gaffney, P. T. Greenlees, R. D. Herzberg, A. Illana, D. T. Joss, J. Konki, T. Kröll, J. Ojala, R. D. Page, P. Rahkila, K. Ranttila, J. Thornhill, J. Tuunanen, P. Van Duppen, N. Warr, and J. Pakarinen, Eur. Phys. J. A 54, 42 (2018).

[19] http://www.nutaq.com
[20] M. A. Ijaz, C. R. Bingham, H. K. Carter, E. L. Robinson, and K. S. Toth, Phys. Rev. C 15, 2251 (1977).

[21] P. Hansen, H. Nielsen, K. Wilsky, M. Alpsten, M. Finger, A. Lindahl, R. Naumann, and O. Nielsen, Nucl. Phys. A 148, 249 (1970).

[22] F. Ibrahim, J. Genevey, E. Cottereau, A. Gizon, A. Knipper, F. Le Blanc, G. Marguier, J. Obert, J. Oms, J. Putaux, B. Roussière, J. Sauvage, and A. Wojtasiewicz, Eur. Phys. J. A 10, 139 (2001).

[23] R. D. Harding et al., Phys. Rev. C 102, 024312 (2020).

[24] T. Kibédi, T. Burrows, M. Trzhaskovskaya, P. Davidson, and C. Nestor, Nucl. Instrum. Methods Phys. Res., Sect. A 589, 202 (2008).

[25] Y. Zhang, F. Xu, J. He, Z. Liu, X. Zhou, Z. Gan, T. Hayakawa, M. Oshima, T. Toh, T. Shizuma, J. Katakura, Y. Hatsukawa, M. Matsuda, H. Kusakari, M. Sugawara, K. Furuno, T. Komatsubara, T. Une, S. Wen, and Z. Wang, Eur. Phys. J. A 14, 271 (2002).

[26] M. Wang, G. Audi, F. G. Kondev, W. Huang, S. Naimi, and X. Xu, Chin. Phys. C 41, 030003 (2017).

[27] B. Pfeiffer, K. Venkataramaniah, U. Czok, and C. Scheidenberger, At. Data Nucl. Data Tables 100, 403 (2014).

[28] C. Weber, G. Audi, D. Beck, K. Blaum, G. Bollen, F. Herfurth, A. Kellerbauer, H.-J. Kluge, D. Lunney, and S. Schwarz, Nucl. Phys. A 803, 1 (2008).

[29] C. M. Baglin, Nucl. Data Sheets 99, 1 (2003).

[30] B. Andel, Study of neutron deficient polonium isotopes, $\mathrm{Ph} . \mathrm{D}$. thesis, Comenius University in Bratislava, Bratislava, 2016.

[31] J. H. Hamilton, A. V. Ramayya, E. L. Bosworth, W. Lourens, J. D. Cole, B. Van Nooijen, G. Garcia-Bermudez, B. Martin, B. N. S. Rao, H. Kawakami, L. L. Riedinger, C. R. Bingham, F. Turner, E. F. Zganjar, E. H. Spejewski, H. K. Carter, R. L. Mlekodaj, W. D. Schmidt-Ott, K. R. Baker, R. W. Fink, G. M. Gowdy, J. L. Wood, A. Xenoulis, B. D. Kern, K. J. Hofstetter, J. L. Weil, K. S. Toth, M. A. Ijaz, and K. F. R. Faftry, Phys. Rev. Lett. 35, 562 (1975).

[32] J. D. Cole, A. V. Ramayya, J. H. Hamilton, H. Kawakami, B. van Nooijen, W. G. Nettles, L. L. Riedinger, F. E. Turner, C. R. Bingham, H. K. Carter, E. H. Spejewski, R. L. Mlekodaj, W. D. Schmidt-Ott, E. F. Zganjar, K. S. R. Sastry, F. T. Avignone, K. S. Toth, and M. A. Ijaz, Phys. Rev. C 16, 2010 (1977).

[33] R. Béraud, M. Meyer, M. Desthuilliers, C. Bourgeois, P. Kilcher, and J. Letessier, Nucl. Phys. A 284, 221 (1977).

[34] J. O. Rasmussen, Phys. Rev. 113, 1593 (1959).

[35] F. Kondev, S. Juutinen, and D. Hartley, Nucl. Data Sheets 150, 1 (2018).

[36] H. Schuessler, E. Benck, F. Buchinger, and H. Carter, Nucl. Instrum. Methods Phys. Res., Sect. A 352, 583 (1995). 